\title{
The Evolution of Sibilants in Polish and Russian
}

\author{
Jaye Padgett and Marzena Zygis \\ University of California, Santa Cruz \& Zentrum für Allgemeine Sprachwissenschaft, Berlin \\ padgett@ucsc.edu \& marzena@zas.gwz-berlin.de
}

\begin{abstract}
In this paper we provide an account of the historical development of Polish and Russian sibilants. The arguments provided here are of theoretical interest because they show that (i) certain allophonic rules are driven by the need to keep contrasts perceptually distinct, (ii) (unconditioned) sound changes result from needs of perceptual distinctiveness, and (iii) perceptual distinctiveness can be extended to a class of consonants, i.e. the sibilants.

The analysis is cast within Dispersion Theory by providing phonetic and typological data supporting the perceptual distinctiveness claims we make.
\end{abstract}

\section{$1 \quad$ Introduction}

Around the sixteenth century, Polish experienced a seemingly odd sound change. Its series of palatalized palatoalveolars depalatalized, and more unexpectedly, became retroflexes: $\left[\widehat{\left[\mathrm{t}^{\mathrm{j}}\right.}, \mathrm{\rho}^{\mathrm{j}}, 3^{\mathrm{j}}\right]>[\overrightarrow{\mathrm{tss}}, \mathrm{s}, \mathrm{z}]$. A similar change occurred in Russian about two centuries earlier. These changes were most likely independent. In this paper, we provide an account of retroflexion within the framework of Dispersion Theory (Flemming 1995, to appear, Padgett 2003a, b). Following Zygis (2003b), we argue that retroflexion was motivated by contrast dispersion. ${ }^{1}$ Specifically, Polish had earlier developed the alveolopalatal sibilants [t.s, $, \varphi, z]$, from a series of palatalized dentals. This resulted in a contrast between palatalized palatoalveolars and alveolopalatals, e.g., $\left[\left[_{\mathrm{tg}}\right]\right.$ versus $[\widehat{[t}]$ and so on. Such a contrast, we argue, is highly disfavored on perceptual grounds. Polish repaired the problem by depalatalizing, and retroflexing, the palatalized alveolars, creating a much more dispersed contrast among sibilants. The diagram in (1) illustrates the idea. The facts of Russian are more complicated, but similar in the crucial respects.

(1)

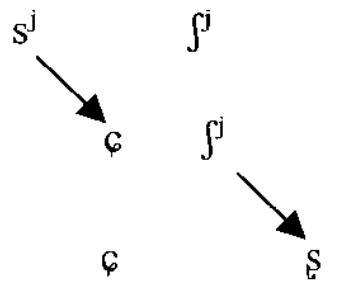

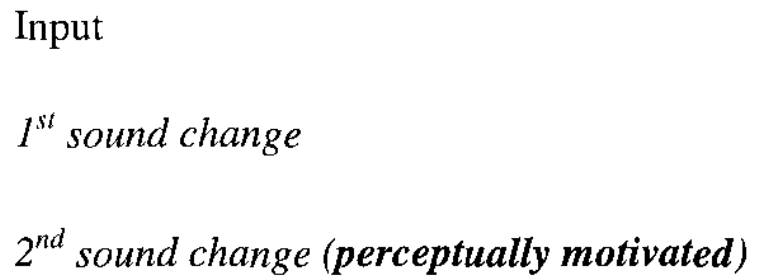

Input

$$
\begin{aligned}
& 1^{\text {st }} \text { sound change } \\
& 2^{\text {nd }} \text { sound change (perceptually motivated) }
\end{aligned}
$$

Besides further motivating the importance of perceptual distinctiveness of contrast for phonology, the arguments here are of theoretical interest in several ways. First, recent work has argued that some allophonic rules are driven by the need to keep contrasts perceptually distinct (Kingston \& Diehl 1994, Padgett 2001, 2002, 2003a, b, Itô \& Mester to appear). The Polish and Russian facts provide another case of this sort: in the modern languages, nonalveolopalatal postalveolar sibilants are allophonically retroflexed, as a result of the sound changes in question. Despite their ubiquity, allophonic processes remain largely mysterious in

Hall (1997a) proposes an explanation for a similar Sanskrit sound change that resembles the present one in some respects. See the discussion in section 6 . 
the context of phonological theory (putting aside assimilatory cases); seeking to explain allophony by appealing to contrast is therefore interesting.

Second, the analysis adds to a long list of sound changes that can be argued to result from needs of perceptual distinctiveness. Retroflexion is one of many 'unconditioned' sound changes, that is, sound changes that occurred regardless of environment. Some pregenerative work notably argued that there $i s$ in fact conditioning for some of these rules - in the paradigmatic system of contrast rather than the syntagmatic environment (see especially Martinet 1952, 1955). However, such functional notions have received much less attention in the generative literature. This is in part because they were not considered precise enough. This paper attempts to redress this shortcoming by casting the analysis within Dispersion Theory, a formal framework for the understanding of contrast, and by providing phonetic and typological data supporting the perceptual distinctiveness claims we make.

Finally, most work on contrast dispersion focuses on vowels and vowel-like sounds (e.g., Liljencrants \& Lindblom 1972, Lindblom 1986). The 'perceptual map' of vowels is better understood than that of consonants, but in principle the same principles apply to consonants as to vowels. This paper is of interest for showing how claims about perceptual distinctiveness can be extended to a class of consonants, the sibilants.

\section{Theoretical framework}

Though we provide a few remarks here, we assume a general familiarity with Dispersion Theory (Flemming 1995, 2002), further developed in Padgett (2002a, b) and with Optimality Theory (Prince \& Smolensky 1993), in which it is cast. For more work within Dispersion Theory see Bradley (2001), Ní Chiosáin and Padgett (2001), Sanders (2003), Minkova \& Stockwell (2003), and Itô \& Mester (to appear).

What distinguishes Dispersion Theory is the assumption that forms must be evaluted with respect to other contrasting forms rather than in isolation. For example, whether a form like [ $\mathrm{Sa}$ ] is licit in a language depends in part on whether contrasting forms such as [sa] or [6a] are possible in that language, as we will see. Given Richness of the Base (Prince and Smolensky 1993), and this systemic view of wellformedness, the input to any tableau in Dispersion Theory is, in the simplest (but daunting) view, the set of all possible words. Candidate outputs are also sets of words - subsets of this rich input. In practice, analyses employ idealizations that are severe enough to be manageable, and vast numbers of possible forms can be safely ignored. The point of all of this is to make possible the evaluation of the perceptual distinctiveness of contrast, and of the preservation of contrast itself, notions that intrinsically appeal to more than one form at a time. The former is handled by means of a family of SPACE constraints, which require minimal pairs to be perceptually distinct to various degrees; the latter by a constraint *MERGE, requiring forms that are distinct in the input to remain distinct in the output. SPACE constraints are systemic markedness constraints, and *Merge, a systemic faithfulness constraint. So Dispersion Theory fits within Optimality Theory in the following way (adapted from Itô \& Mester to appear):

Constraints in Optimality Theory

\begin{tabular}{|l|l|l|}
\cline { 2 - 3 } \multicolumn{1}{c|}{} & Markedness & Faithfulness \\
\hline Standard & ONSET, *[-son, +voice], WSP, ... & MAX, DEP, IDENT, ... \\
\hline Systemic & SPACE & $*$ MERGE \\
\hline
\end{tabular}


Though Dispersion Theory can be made less daunting by employing extreme idealization (as we will see here), the idea that the input is the set of all possible forms raises certain questions, assuming that the number of possible forms is infinite. ${ }^{2}$ Given an infinite input, we have the possibility of infinite constraint violations. For example, there are an infinite number of inputs like $/ \mathrm{ba} /, / \mathrm{baba} /, / \mathrm{bababa} /$, and so on; assuming they remain distinct in the output, we have potentially an infinite number of violations of * [-son, +voice], for one candidate set of forms. This can lead to a state of affairs in which candidates each having an infinite number of violations of some constraints are being compared, leading to indeterminacy of the output. As far as we can see, the only way to avoid this result is to assume an upper limit on the length of possible forms, both in the input and in candidate outputs. Though Richness of the Base is often said to imply no restrictions on inputs, in fact what it implies is no languageparticular restrictions on the input. In order for constraints to be able to evaluate forms, the latter must respect universal principles of phonological form: feet must contain syllables and not vice versa, and so on. Though generativists have long held that linguistic forms are indefinitely long (Chomsky 1957), it is not incompatible with the recursive nature of grammar to impose as a filter a (possibly very large) upper limit on string length, something that can be grounded in memory limitations. This move eliminates the problem of infinite constraint violations. This is obviously an issue that deserves more exploration.

\section{$3 \quad$ Polish historical facts}

The inventory of Polish consonants is given below. We will be particularly interested in the Polish sibilants, shown in the box. The highlighted phonemes are shown twice. On the one hand, they behave as the palatalized correspondents of $/ \mathrm{t}, \mathrm{d} / \mathrm{in}$ Polish phonology. On the other, they are sibilants, and for our purposes we must see how they fit into the sibilant inventory.

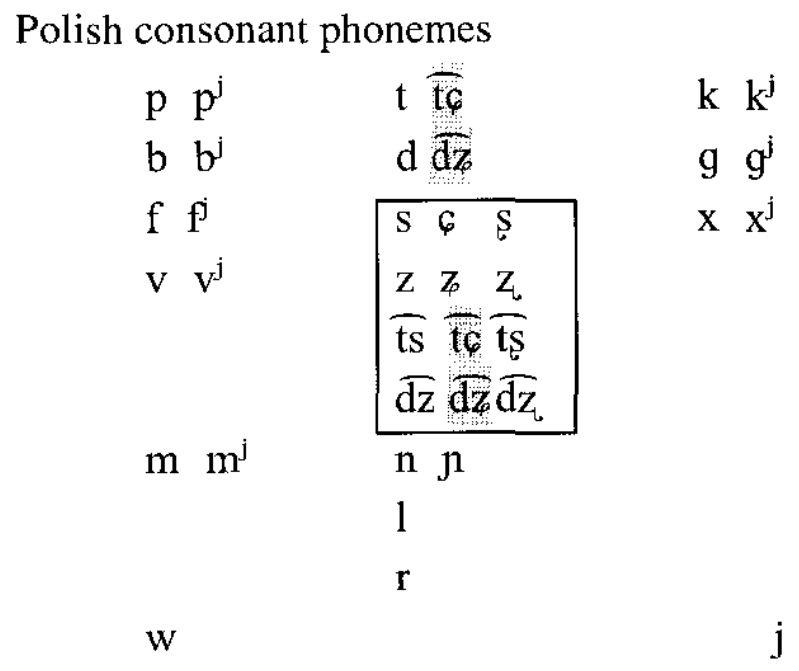

Abstracting away from differences in voicing and manner, Polish has the three sibilant series shown below. Note that we will use 'postalveolar' as a general term for alveolopalatals, retroflexes, and also palatoalveolars like [f].

Thanks to John McCarthy and Alan Prince for raising this issue. 


\begin{tabular}{|c|c|c|}
\hline Dental/Alveolar & Alveolopalatal & Retroflex \\
\hline $\mathrm{S}$ & 6 & $\mathrm{~S}$ \\
\hline
\end{tabular}

The Polish alveolopalatals arose historically from a palatalized dental series that once existed in Polish (Stieber 1968, 1962, Rospond 1971), as shown in (5). This occurred in roughly the $13^{\text {th }}$ century. This is a common change for palatalized dentals or alveolars to undergo, and can be seen in Russian dialects, in Irish dialects, and in Japanese (see Padgett 2001 for discussion).

(5) Palatalized dentals became alveolopalatals (roughly $13^{\text {th }}$ century)

$$
\begin{aligned}
& \text { Old Slavic } 13^{\text {th }} \text { century } \\
& \mathrm{t}^{\mathrm{j}}, \mathrm{d}^{\mathrm{j}}, \mathrm{s}^{\mathrm{j}}, \mathrm{z}^{\mathrm{j}}>\overparen{\mathrm{t} \varphi}, \widetilde{\mathrm{d} z}, \mathrm{c}, \mathrm{z} \\
& \mathrm{i}\left[\mathrm{d}^{\mathrm{j}}\right] \mathrm{e}\left[\mathrm{t}^{\mathrm{j}}\right] \mathrm{e}>\quad \mathrm{i}[\overrightarrow{\mathrm{d} z}] \mathrm{e}[\mathrm{t} \epsilon] \mathrm{e} \quad \text { 'you go' Pl. Stieber }(1962: 63) \\
& {\left[\mathrm{s}^{\mathrm{j}}\right] \mathrm{eja}\left[\mathrm{t}^{\mathrm{j}}\right] \mathrm{i}>\quad[\mathrm{c}] \mathrm{a}[\widehat{\mathrm{t} c}] \quad \text { 'to sowl' Carlton (1991:342) }} \\
& {\left[z^{j} \text { ]emja }>\right.\text { [7] emia 'soil' Carlton (1991:345) }}
\end{aligned}
$$

Our primary interest is in a subsequent sound change. Around the $16^{\text {th }}$ century, a series of palatoalveolars that had existed since the time of Common Slavic underwent an 'unconditioned' change to retroflex, as shown below (examples from Rospond, pp. 91, 110 ff.). It should be noted that palatoalveolars in Old Polish and Old Russian occurred only palatalized. This is because they derived from the palatalizing mutation of velars when adjacent to front vocoids, where those velars likely bore secondary palatalization, i.e.,

\begin{tabular}{|c|c|c|c|}
\hline$\left[\mathrm{tg}^{\mathrm{i}} \mathrm{i}\right]$ sto & $>$ & $\widehat{[t S \dot{1}}]$ sto & 'clean' \\
\hline$\left[\int^{\mathrm{j}} \mathrm{i}\right] \mathrm{ja}$ & $>$ & [și & 'neck' \\
\hline$\left[3^{j^{j}}\right]$ to & $>$ & {$[\mathrm{z} \dot{\mathrm{i}}]$ to } & 'rye' \\
\hline
\end{tabular}
$\mathrm{k}^{\mathrm{j}}, \mathrm{g}^{\mathrm{j}}, \mathrm{x}^{\mathrm{j}}>\widehat{\mathrm{t} \mathrm{j}^{\mathrm{j}}}, 3^{\mathrm{j}}, \mathrm{j}^{\mathrm{j}}$, respectively. So the change of interest here involved both depalatalization and retroflexion. (Polish, like Russian, does not permit [i] to follow non-palatalized sounds, hence the change is in vowel quality.)

(6) Palatalized palatoalveolars became retroflexes (roughly $16^{\text {th }}$ century)

\section{$4 \quad$ Russian historical facts}

The Russian facts are similar in the crucial respects, but show some intriguing differences as well. The consonant inventory is given below. It should be noted that the phonemic status of [6:] and [z:] is often debated, a point to which we will return. ${ }^{3}$

The sounds [६:] and [द:] are usually transcribed with symbols standing for palatalized palatoalveolars, c.g.,

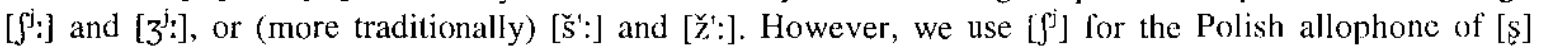
occurring before front vowcls (see section 5). The long Russian sounds in question here are more similar to Polish $[\varphi]$ than they are to Polish $\left[j^{j}\right]$, and for consistency we transcribe them accordingly. We think these transcriptions are more accurate than what is traditional. 
(7) Russian consonant phonemes

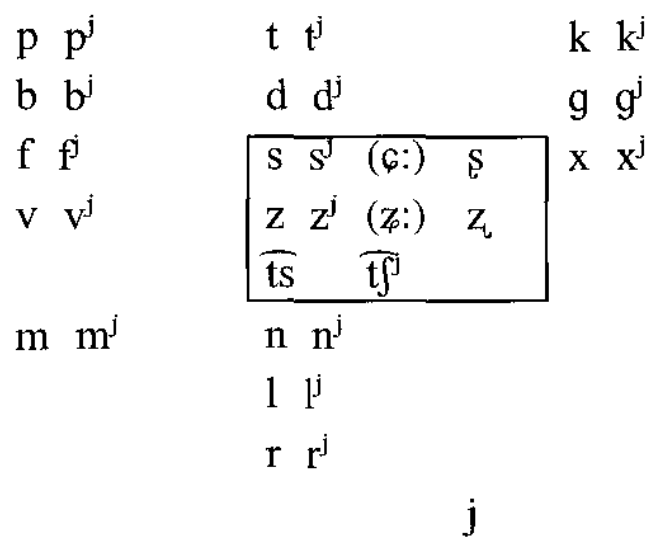

Russian differs from Polish in two relevant ways. First, palatalized dentals did not become alveolopalatals. Compare the Russian and Polish forms below.

$\begin{array}{llll}\begin{array}{lll}\text { Russian } \\ \text { brat }^{\text {j }}\end{array} & \text { 'bring' } & \text { Polish } \\ \text { s'ostr }^{\text {joste }} & \text { 'sisters (gen)' } & & \text { bratc } \\ & & \text { custr }\end{array}$

This raises the question: did the alveolopalatals of Polish motivate the shift from palatoalveolar to retroflex? If so, why did the shift occur in Russian as well? Second, though retroflexion occurred in Russian, it affected only the fricatives, and not the affricate, which remains a palatalized palatoalveolar $\left[\overline{\mathrm{tg}^{\mathrm{j}}}\right]$ today. Why didn't this sound become retroflex too?

The Russian sibilant series are shown below.

(9) Russian sibilant contrasts

\begin{tabular}{|c|c|c|c|}
\hline Dental & Palalized Dental & (Alveolopalatal) & Retroflex \\
\hline $\mathrm{s}$ & $\mathrm{s}^{\mathrm{j}}$ & $(\mathrm{G}:)$ & $\mathrm{S}$ \\
\hline $\mathrm{z}$ & $\mathrm{z}^{\mathrm{j}}$ & $(\mathrm{z}:)$ & $\mathrm{z}$ \\
\hline
\end{tabular}

Russian retroflexion, which occurred around the $14-15^{\text {th }}$ centuries, is illustrated below (Borkovskii \& Kuznetsov 1963, Chernykh 1962).

(10) Palatoalveolar fricatives became retroflexes ( $\approx$ late $14^{\text {th }}$ century)

$$
\begin{array}{llll}
\int^{j} u m u & > & \text { sum } & \text { 'noise' } \\
\text { pokaz }^{j} \mathrm{u} & > & \text { pokazu } & \text { 'I will show' }
\end{array}
$$

The scheme in (11) summarizes the history of the Polish and Russian sibilants; changed forms are given in bold. 
(11) History of sibilant fricatives in Polish and Russian:

Late Common Slavic Late Common Slavic

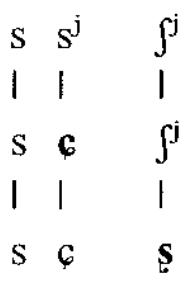

Modern Polish

\begin{tabular}{lll} 
& \multicolumn{2}{c}{ Late Common Slavic } \\
$\mathrm{s}$ & $\mathrm{s}^{\mathrm{j}}$ & $\int^{\mathrm{j}}$ \\
$\mathrm{I}$ & $\mathrm{I}$ & $\mathrm{I}$ \\
$\mathrm{S}$ & $\mathrm{s}^{\mathrm{j}}$ & $\int^{\mathrm{j}}$ \\
$\mathrm{I}$ & $\mathrm{I}$ & $\mathrm{I}$ \\
$\mathrm{s}$ & $\mathrm{s}^{\mathrm{j}}$ & $\mathbf{s}$ \\
& \multicolumn{3}{l}{ Modern Russian }
\end{tabular}

\section{$5 \quad$ Acoustic/Perceptual organization of sibilants}

This section provides phonetic detail on the sibilants in question, as well as phonetic and typological motivation for the claims we make about perceptual distinctiveness.

The Polish alveolopalatals $[\widehat{t \epsilon}, 6, z]$ have a great deal of tongue blade/body raising and fronting - they are inherently strongly palatalized. The cavity in front of the constriction is very small (though not as small as for [s]), and the lips are typically spread (Wierzchowska 1980). The significance of these facts is that alveolopalatals sound 'high pitched', as much hissing as hushing, to use traditional terms. They are higher in tonality than are palatoalveolar $\left[\int, 3\right]$.

Polish and Russian [s, z] are often transcribed as palatoalveolar, but they are different from English [S, 3], more accurately retroflex (Jones \& Ward 1969, Keating 1991, Ladefoged \& Maddieson 1996, Hall 1997b, Ladefoged 2001, Hamann \& Rochoń 2002, Hamann 2003, Zygis 2003 a,b). ${ }^{4}$ They also involve some rounding and possibly velarization. The cavity in front of the constriction is comparatively large, including a significant sublingual cavity, giving these sounds a low tonality compared to [S, 3]. In what follows we make more concrete these tonality differences.

There is much work applying the idea of perceptual distinctiveness to vowels in a rather concrete way, in order to make predictions about sound systems (e.g., Liljencrants and Lindblom 1972, Lindblom 1986, Schwartz, et al. 1997). There is notably less such work in the case of consonants. Consonants are more difficult in part because they can differ significantly from one another in many acoustic dimensions. For example, fricatives can differ from one another in their spectra, formant transitions, length, and intensity. In what follows we make a simplifying assumption that the cues to sibilant place lie exclusively in the fricative noise spectrum itself. Some studies have found that duration, intensity, and formant transitions matter relatively little in distinguishing among sibilants (Hughes \& Halle 1956, Heinz \& Stevens 1961, see overview in Evers, et al. 1998). Others show that formant transitions can matter, though not as much as the noise spectrum (Repp 1981, Mann \& Soli 1991, Whalen 1991, and references therein, 1981). However, the studies cited generally look only at the sibilants [s] versus [f]. Once we add in retroflexes and alveolopalatals, it is quite likely that other cues, particularly formant transitions, will matter. In our favor, however, is the fact that Polish sibilants can occur in non-vocalic contexts, e.g., kla[ps] 'smack' nom.sg., pie[ps]

\footnotetext{
4 They are not as retroflex as retroflex fricatives in some languages of the Indian subcontinent. They are apical and retracted, but not articulated with the underside of the tongue blade. The point is not to defend a particular meaning of 'retroflex', but to make clear that the relevant Polish and Russian sounds differ from palatoalveolars as in English or French.
} 
'pepper' nom.sg., ba[ptढ] 'grandmother' gen.pl. Therefore there must be sufficient cues for distinguishing among them in the fricative noise itself.

The second author carried out center of gravity (COG) measurements of sibilants in Polish, Russian, and Bulgarian (Zygis 2003a, cf. also Zygis and Hamann 2003). The choice of Bulgarian was motivated by the fact that its inventory contains $\int$, i.e. $s s^{j} \int$. The 'center of gravity' is a weighted average frequency, where frequencies at which a fricative has more intensity count more (Jongman, et al. 2000, Gordon, et al. 2002, Forrest, et al. 1988). The measurements involved 4 speakers of each language, all pronouncing ten repetitions of sibilants before the vowel [a]. The fricatives were recorded at a sample rate of $22.05 \mathrm{kHz}$, and COG measurements were taken over the range $0-10 \mathrm{kHz} .^{5}$

Figure (12) shows results for Polish. (These and all following figures show one representative speaker only. For full data see Zygis 2003a, cf. also Zygis and Hamann 2003). COG values in this figure are taken over the entire duration of the fricative, excluding the first and last $5 \%$. It should be noted that the sound $\left[\mathrm{S}^{\mathrm{j}}\right]$ (not indicated in the phoneme inventory above) exists only in loanwords. It occurs exclusively before [i]. Since retroflexes never occur in that environment, $\left[\mathrm{f}^{\mathrm{j}}\right]$ is probably best regarded as an allophone of $/ \mathrm{s} /$.

Polish COG values of $s, 6, \mathrm{j}^{\mathrm{j}}$, s (speaker AT).

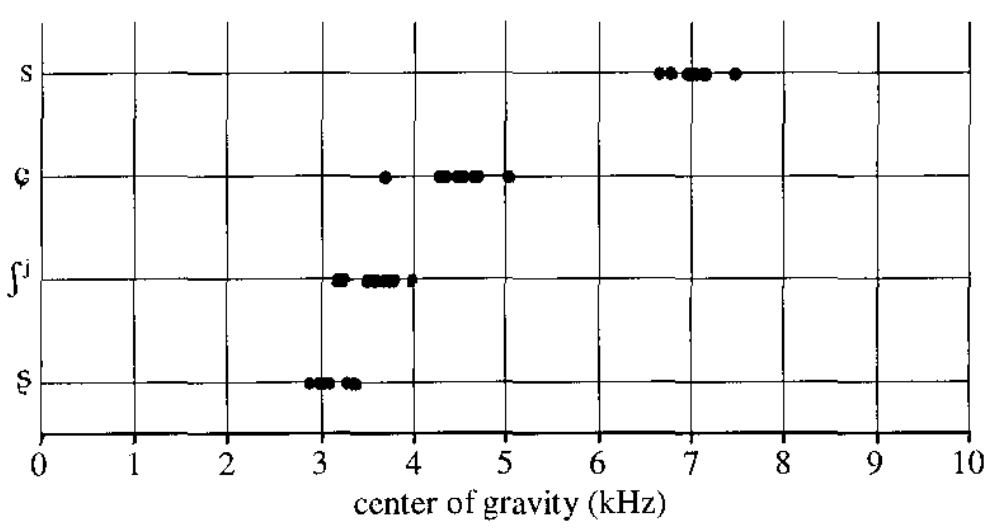

As can be seen, [s] stands apart in having a very high COG value. Among the postalveolars, the ordering is [G]> [f] $>$ [s], from highest to lowest. These three segments are notably closer together, even overlapping.

Figure (13) shows COG values for these fricatives as they change over time, distinguishing the first, middle, and last third of the fricative duration (excluding once again the first and last 5\%). Here there is little more of note, but the relevance of looking at the time course will be clear for Russian and Bulgarian.

Thanks to Silke Hamann and Paul Boersma for the use of the scripts they designed for Zygis and Hamann (2003). 
(13) Time-varying COG values of Polish (speaker AT).

From the top: $[\mathrm{s}]=$ solid line, $[\mathrm{c}]=$ dashed line, $\left[\mathrm{f}^{\mathrm{j}}\right]=$ dotted line, $[\mathrm{s}]=$ solid line.

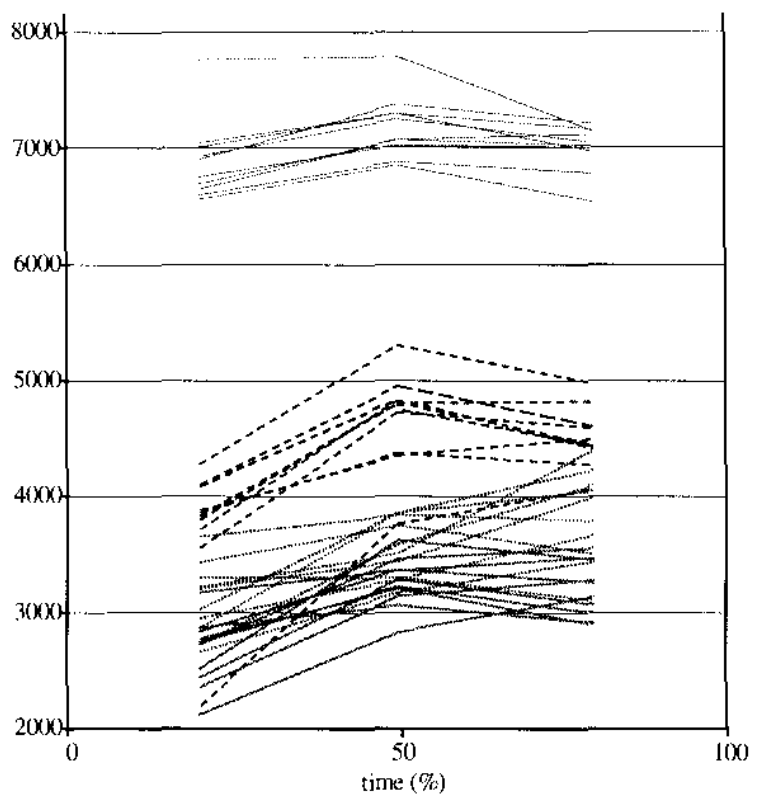

Bulgarian has the sibilants [s] and [s $\mathrm{s}^{\mathrm{j}}$, like Russian, but also plain [f], unlike Russian or Polish. COG results for Bulgarian appear below. Once again we see that [s] and [S] are relatively far apart. $\left[\mathrm{s}^{j}\right]$ is quite close to [s], even overlapping with it.

COG values of Bulgarian $s, s^{j}, \int$ (speaker HV).

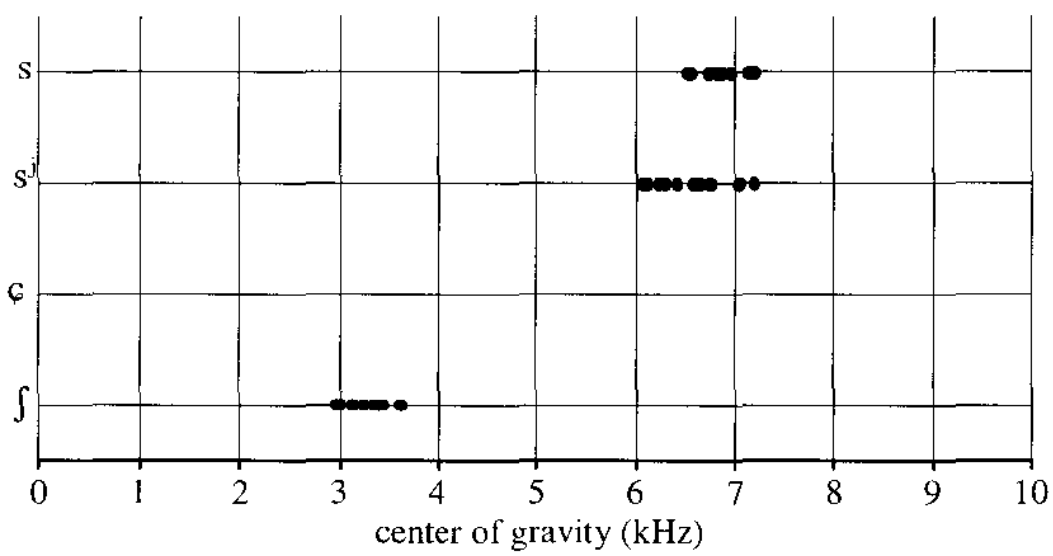

However, the time-varying measurments reveal more. For some speakers, at least, though $\left[\mathrm{s}^{\mathrm{j}}\right.$ ] begins very much like [s], its COG value can drop a great deal towards the end, so that it is much more like [f]. This is shown for speaker HV in (15). However, other speakers show this drop less or not at all. Zsiga $(1995,2000)$ found a similar drop in English [f] before [j], and proposed a gestural overlap account: [j] exerts a coarticulatory effect on [s], so that /s/ becomes progressively more like [ $]$ ] towards its end. It seems likely that coarticulatory effects such as these lead to phonologized alternations like $/ \mathrm{s} / \rightarrow[j]$ or $[\varphi]$ before front vocoids, of the sort seen in many languages. The relevance here is the following: to the extent that such coarticulation happens, $\left[\mathrm{s}^{\mathrm{j}}\right]$ and []] are more alike than might seem evident from transcriptions, and this might help us understand why retroflexion occured in Russian despite the fact that $\left[\mathrm{s}^{\mathrm{j}}\right]$ remained $\left[\mathrm{s}^{\mathrm{j}}\right]$ rather than becoming $[\mathrm{c}]$. 
(15) Time-varying COG values of Bulgarian (speaker HV).

From the top: $[\mathrm{s}]=$ solid line, $\left[\mathrm{s}^{\mathrm{j}}\right]=$ dotted line, $\left[\int\right]=$ solid line

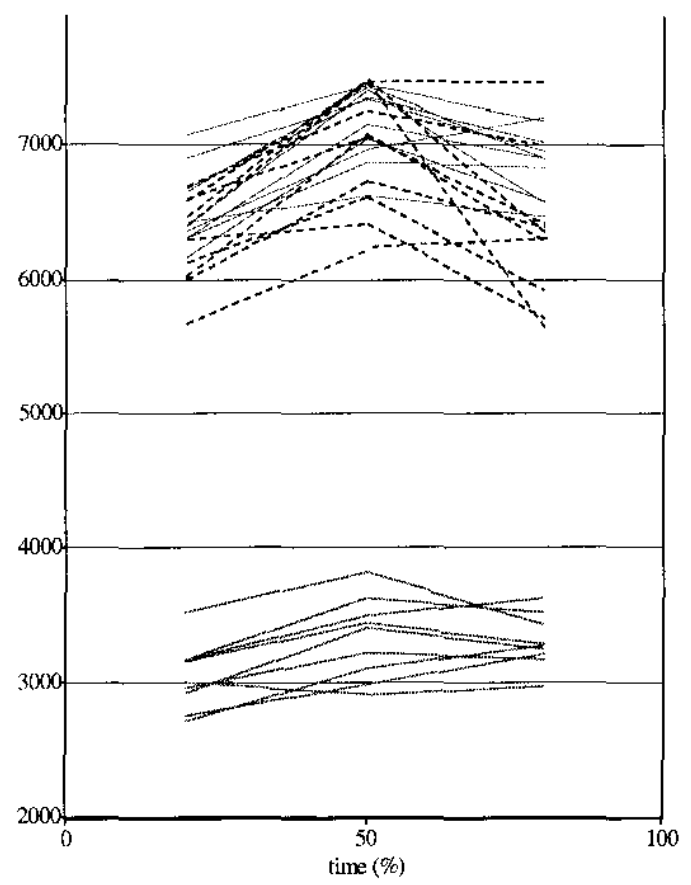

Finally, (16) shows COG values for the Russian sibilants, including the sound [c:] whose phonemic status is debatable (see discussion in section 7). These results seem largely familiar from what we have seen above.

(16) COG values of Russian $s, s^{j}, 6 i, s$ (speaker VB).

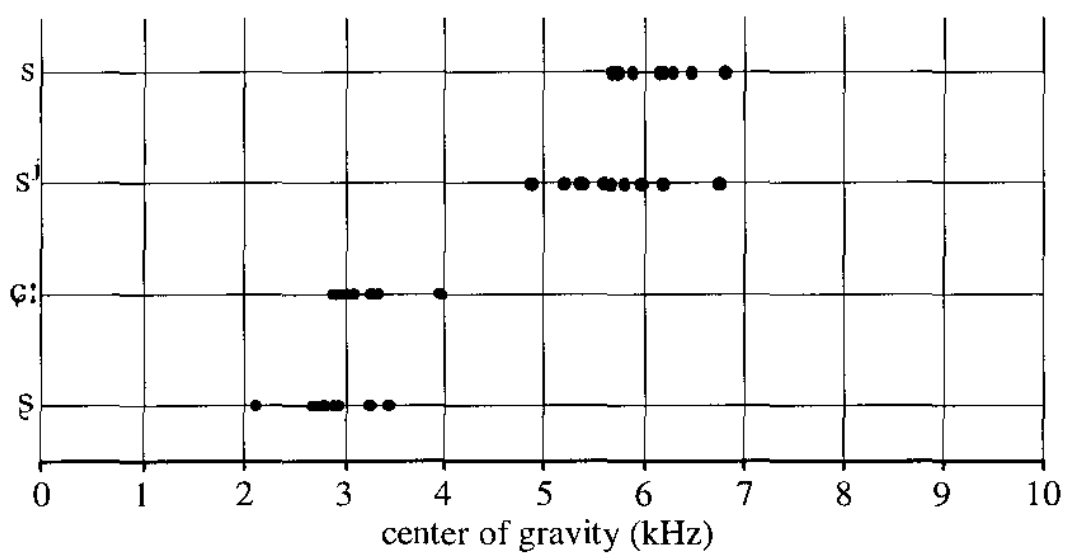

The time-varying measurements suggest that $\left[\mathrm{s}^{\mathrm{j}}\right]$ can become acoustically more like a postalveolar towards the end of its articulation. However this occurs only for one speaker and to a lesser degree than in the Bulgarian data: 
(17) Time-varying COG values of Russian

From the top: $[\mathrm{s}]=$ solid line, $\left[\mathrm{s}^{\mathrm{j}}\right]=$ dashed line, $[\mathrm{c}:]=$ dotted line, $[\mathrm{s}]=$ solid line.

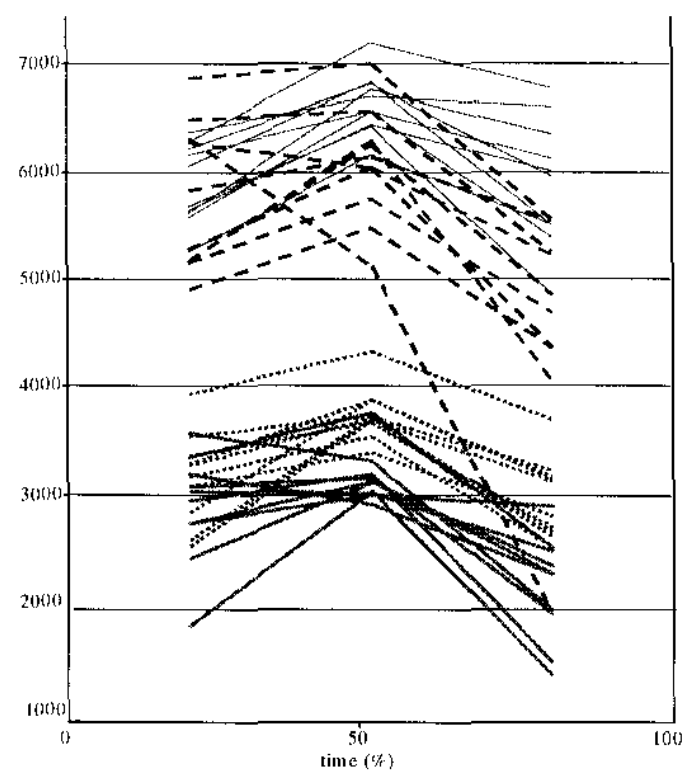

The ordering among sibilants indicated by these COG results is given in (18)a-c. (18)d puts these orderings together, showing the relative ordering from highest $\mathrm{COG}[\mathrm{s}$ ] to lowest [s]. Note in particular that, among postalveolars, palatalveolars like $\left[\mathrm{S} / \mathrm{S}^{\mathrm{j}}\right]$ lie in between the higher alveolopalatals and lower retroflexes. We treat $\int$ and $\int{ }^{j}$ together because in contrast to other sibilants their COG values strongly overlap, cf. Bulgarian $\int$ with Polish $\int^{\mathrm{j}}$. This explains why the two sounds do not contrast in the languages examined here.

(18) Ordering of sibilants resulting from COG measurements:
a) Polish:
b) Bulgarian:
$\begin{array}{llll}\mathrm{s} & 6 & \mathrm{j}^{\mathrm{j}} & \mathrm{S}\end{array}$
c) Russian
$s \quad s^{j} \quad \int$
d) Overall:

$S \quad S^{j} \quad$ G: $\quad S$
$\begin{array}{lllll}S & S^{j} & 6 & \int / s^{j} & s\end{array}$

Of equal interest, our results suggest that the postalveolars might be perceptually relatively close together, in comparison to the distance between [s] and any postalveolar. (See (12), (13), (16), and (17).) There is some COG overlap between [6] and [ $\left.\int\right]$ on the one hand, and between [S] and [S] on the other, suggesting these contrasts might be especially disfavored. Taken together, the COG results suggest a picture somewhat like that in (19)a. If this is correct, then we can understand why the change in Polish, from (19)b to (19)c, would be perceptually favored. The analysis next section will develop this idea.
a. $\mathrm{S}$
$6 \quad \int / \int^{\mathrm{i}} \quad \mathrm{S}$
b. $\mathrm{s}$
$6 \quad \rho^{j}$
c. $\mathrm{S}$
6
s

An important limitation of these results should be acknowledged. Though the COG results support the picture given in (18) and (19), these results are purely acoustic, and cannot tell us directly what the perceptual facts are. We are piloting perceptual experiments to test these same claims. 
On the other hand, a consideration of the typology of sibilants provides support for these conclusions from an independent angle. Before turning to the phonological analysis, let us consider these facts.

First, as is well known, the most common sibilant, and fricative, in inventories is [s] (whether dental or alveolar). Most languages with a postalveolar sibilant have [s] too (Maddieson 1984). If we can draw conclusions about perceptual distinctiveness from such facts, the fact that [s] contrasts freely with all postalveolar sibilants suggests that the anterior versus non-anterior contrast is perceptually robust.

Second, the most common sibilant contrast is [s] versus [f]. [f] is the unmarked postalveolar sibilant (Maddieson 1984).

Of more direct relevance are potential contrasts among postalveolars. Consider first the contrast alveolopalatal versus retroflex, e.g., [G] versus [s]. This contrast occurs not only in Modern Polish, but in Serbian dialects (Zygis 2003a), Komi Permyak(Kochetov and Lobanova 2003), Mandarin (Ladefoged \& Maddieson 1996), Pekingese (cited in Hall 1997a), Telegu (Maddieson 1984), and Malayalam (Mohanan, p.c.). This fact is of some interest, since it points up a markedness paradox: if palatoalveolars like [ $\int$ ] are the least marked postalveolars by other criteria (frequency in language, and the usual choice of a language having only one postalveolar), how can it be that some languages have only [6] and [s]? The answer, we maintain, is that given a contrast to be maintained between two postalveolars, [6] versus [s] is perceptually optimal.

What of contrasts between [S] and either of the other two postalveolar types? Our comments here rely on the references cited, and on an examination of the most recent UPSID database (Maddieson \& Precoda 1992). Relatively few languages are claimed to contrast [f] versus [s] (or their voiced or affricate counterparts), as Keating (1991) notes. Hall (1997a) cites Tolowa, Toda, and Basque. There are about 10 according to UPSID, e.g. Acoma, Pashto, Tarascan. However, the answer is complicated by having to rely on transcriptions supplied by grammars. Judging from recordings supplied in Ladefoged (2001), Toda ' $\int$ ' is impressionistically more like [6]. In a similar vein, Basque ' $s$ ' is not obviously retroflex, though it is apical (Trask 1997), and Basque ' $\int$ ' may be more similar to [6] (Hualde, p.c.). The problem is that sounds like [c] and [s] are often transcribed as though palatoalveolars in grammars, for reasons of convention, typography, or a lack of interest in postalveolar details. So a real assessment of the facts will require careful descriptions or acoustic data. A conservative position would seem to be that contrasts like [f] versus [s] might well exist, though they are not common.

A similar conclusion holds for [6] versus [5]. Hall (1997a) cites Syränisch, Livonian, Morksha Mordvinian and Erza Mordvinian as languages that are said to have this contrast, though he notes the lack of detailed phonetic description in support of this claim. However, Polish did maintain this contrast before retroflexion occurred, as detailed earlier.

Finally, if contrasts like [\$] versus [s] and [G] versus [§] are possible, then we would expect that all three might occur together. We know of no cases, but since contrasts involving even two postalveolars are not frequent, we cannot draw any conclusions. However, the very fact that such contrasts are uncommon in comparison to contrasts like [s] versus [f] provides more support for the claims made here about perceptual distinctiveness. The next section turns to a Dispersion-Theoretic analysis of Polish retroflexion. 


\section{Analysis of Polish retroflexion}

Focusing just on the postalveolar sibilants, the diagram in (20) indicates the hypothesized spacing of these sounds depending on the number in contrast. More contrasting segments means less space for each.

Spacing of postalveolar sibilants

\begin{tabular}{|c|c|c|c|}
\hline 6 & $\int$ & $S$ & Each segment gets $1 / 3$ of the perceptual space \\
\hline 6 & \multicolumn{2}{|c|}{$\mathrm{S}$} & Each segment gets $1 / 2$ of the perceptual space \\
\hline \multicolumn{2}{|c|}{$\int$} & Each segment gets $1 / 1$ of the perceptual space \\
\hline
\end{tabular}

The SPACE constraint below follows Ní Chiosáin \& Padgett (2001) in general form, extending the family to the postalveolar sibilant domain. For lack of a better term, we use ' $\mathrm{COG}$ ' to refer to the relevant acoustic-perceptual dimension, the tonality of the fricative noise. (Distinctions among these sounds are not captured in a unitary way by distinctive features.)

\section{SPACE $_{C O G} \geq 1 / \mathrm{n}$ : Potential minimal pairs differing in COG differ by at least $1 / n$th of the full COG range.}

'Potential minimal pairs' are pairs of words, such as [afa] and [aca], having the form of a minimal pair (see Padgett 2003a for more explicit discussion). Whether a potential minimal pair actually represents a possible contrast depends on the language, and is in part up to the ranking of SPACE constraints. ${ }^{6}$

Following usual assumptions in Dispersion Theory, we project a family of SPACE COG constraints, shown below. This ranking is universal, expressing the universal dispreference for contrasts as they become more crowded. The lowest-ranked constraint, SPACE $\operatorname{COC} \geq 1 / 1$, is the most demanding, requiring in effect that a sound have the entire perceptual space to itself, a demand inconsistent with contrast. The highest-ranked, SPACE $\operatorname{COG} \geq 1 / 3$, requires that sounds differ by at least $1 / 3$ of the full range, as in the top row of (20). It seems safe to say that this constraint is universally respected - that a contrast of four or more postalveolar places is impossible. Therefore this constraint is in GEN, and only SPACE ${ }_{C O G} \geq 1 / 2$ and SPACE COG $\geq 1 / 1$ are among the rankable constraints.

$$
\text { SPACE } \left._{\mathrm{COG}} \geq 1 / 3\right] \gg \operatorname{SPACE}_{\mathrm{COG}} \geq 1 / 2>\operatorname{SPACE}_{\mathrm{COG}} \geq 1 / 1
$$

Dispersion Theory assumes that all constraints are grounded, whether perceptually, articulatorily, or otherwise. We assume that the articulatory facts motivate the following constraint ranking universally. That is, the strong inherent palatalization of [c], and the retroflexion of [s], make these more difficult segments to produce in comparison to [S].

$$
\text { Articulatory markedness: }{ }^{*},{ }^{*},>*_{S}
$$

Consider first the simple scenario in which faithfulness to place of articulation is paramount, as shown below. Though the input to a tableau (as discussed in section 2) is the

This formulation of SPACE means that a pair such as [srat] versus [cap] is not compared, since it is not a minimal pair. However, SPACE will still regulate such words, because they contrast with the possible words lcat] and [srap], respectively. It is irrelevant, note, whether thesc are actual or merely possible words. 
rich base - all possible words in principle - our idealization abstracts away from everything but the relevant postalveolar distinctions, considering only words of the form [Ca], where $\mathrm{C}$ is one of $\left[\varphi, \int, s\right]$. IDENT in this tableau refers to whatever features cover these postalveolar distinctions. As should be clear, with Ident undominated, the full output contrast will be chosen. Taking up our discussion above, we assume this to be possible.

Full contrast: High ranking faithfulness

\begin{tabular}{|c|c|c|c|c|c|}
\hline Input: & ca $\int \mathrm{a}$ sa & IDENT & SPACE $\geq 1 / 2$ & SPACE $\geq 1$ & $*_{6} / *_{S}$ \\
\hline a. & ca $\int a$ sa & & $x \times$ & $* * *$ & ** \\
\hline b. & ca $\int a$ & $* !$ & 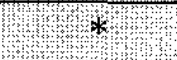 & 乘 & 1 \\
\hline c. & Sa sa & $* !$ & 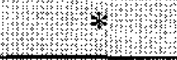 & $x$ & $*$ \\
\hline d. & ca $\quad$ sa & $* !$ & 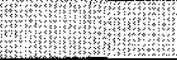 & X & ** \\
\hline e. & $6 \mathrm{a}$ & $* ! *$ & & (l) & * \\
\hline
\end{tabular}

More interesting is the case where Ident is dominated by SPACE $\geq 1 / 2$ (but not SPACE $\geq 1$ ), seen in (25). The result is dispersed contrast, as in Polish, Pekingese, and so on. Here underlying $/ \mathrm{Sa}$ / neutralizes to either [6a] or [sa] (the choice of output is not relevant here).

$$
\text { Dispersed contrast: } \text { SPACE } \geq 1 / 2>\text { IDENT }>\text { SPACE } \geq 1
$$

\begin{tabular}{|c|c|c|c|c|c|}
\hline Input: & 6a $\int \mathrm{a}$ sa & SPACE $\geq 1 / 2$ & IDENT & SPACE $\geq 1$ & $*_{\phi} / *_{\mathrm{S}}$ \\
\hline a. & ca $\int a$ şa & $* ! *$ & & $* * x$ & ** \\
\hline b. & $6 \mathrm{a} \int \mathrm{a}$ & $* !$ & $*$ & $*$ & $*$ \\
\hline c. 畹 & $6 \mathrm{a}$ & & $*$ & * & $4 *$ \\
\hline d. & $6 \mathrm{a}$ & & $* * !$ & & * \\
\hline
\end{tabular}

If both SPACE constraints dominate faithfulness, then contrast is ruled out. In that case, the choice of sibilant will be up to the articulatory markedness constraints. These favor the palatoalveolar, as seen below. Other rankings of these constraints can favor [ca] versus [ $\mathrm{Sa}$ ], or [ $\int \mathrm{a}$ ] versus [sa] (if $*_{S}$ or ${ }^{*}{ }_{6}$ are undominated respectively, a possibility made available by other theories too). Unless more is said, the possibility of lone [ca] or lone [sa] is ruled out. ${ }^{7}$

Probably more needs to be said. Languages having alveolopalatals like [c] as their sole postalveolar place of articulation occur at least as a side-effect of a palatalization contrast, as in Japanese $/ \mathrm{s}^{\mathrm{j}} / \rightarrow[\mathrm{c}]$. In such cases, the pattern occurs at the surface, though arguably not underlyingly. There are also languages having retroflexes as their sole postalveolar fricative - when part of a series of retroflex consonants. What both facts suggest is that when a language maintains a feature or gesture such as palatalization or retroflexion, independently of sibilants, it can be extended to postalveolar sibilants, thus favoring lone $[s]$ or $[\epsilon]$ instead of expected [S]. 


\begin{tabular}{|lccc|c|c|c|c|}
\hline Input: & ca & fa & sa & SPACE $\geq 1 / 2$ & SPACE $\geq 1$ & IDENT & $*_{c} / *_{\mathrm{S}}$ \\
\hline a. & ca & fa & sa & $* ! *$ & $* * *$ & & $* *$ \\
\hline b. & ca & fa & & $* !$ & $*$ & $*$ & $*$ \\
\hline c. & ca & & sa & & $* !$ & $*$ & $* *$ \\
\hline d. & ca & & & & & $* *$ & $* !$ \\
\hline e. & & sa & & & & $* *$ & \\
\hline f. & & & sa & & & $* *$ & $* !$ \\
\hline g. & & fa & sa & $* !$ & $*$ & $*$ & $*$ \\
\hline
\end{tabular}

One important advantage of Dispersion Theory is its explanation of 'markedness paradoxes' like that discussed last section. In many cases, the paradox is resolved once markedness is factored into separate and potentially conflicting perceptual and articulatory components. For the case at hand we can say that [f] is the most frequent postalveolar place, and the one preferred when there is only one, because it is articulatorily least marked. However, when there is a contrast in the postalveolar region, perceptual markedness (SPACE) prefers dispersion, that is, [c] versus [s]. No theory of markedness that fails to recognize the perceptual side can account for languages like Polish and Pekingese. This argument can be compared to that made by Flemming (1995) concerning high vowels, as illustrated in (27). When high vowels contrast, it is the dispersed contrast we find, [i] versus [u]. In the (uncommon) case where they do not, languages choose a more central -articulatorily simplervowel.

Markedness reversals among high vowels and postalveolar sibilants.

\begin{tabular}{|l|ccc|ccc|}
\hline Contrast: & i & & u & c & & s \\
\hline No contrast: & & i & & S \\
\hline
\end{tabular}

Consider once again the Polish retroflexion sound change, illustrated below.

Input contrasts

$\begin{array}{lll}\mathrm{s} & c & \rho^{\mathrm{j}} \\ \frac{\mathrm{z}}{\mathrm{ts}} & \frac{\mathrm{z}}{\mathrm{tc}} & \frac{3^{\mathrm{j}}}{\mathrm{tg}} \\ \frac{\mathrm{dz}}{\mathrm{dz}} & \frac{\mathrm{d}^{\mathrm{j}}}{\mathrm{d}}\end{array}$
Output contrasts

\begin{tabular}{|c|c|}
\hline $\mathrm{s}$ & 6 \\
\hline $\mathrm{Z}$ & $\mathbf{z}$ \\
\hline & \\
\hline
\end{tabular}

Before the $16^{\text {th }}$ century, Polish contrasted the perceptually disfavored [6] versus [ $\rho^{\mathrm{j}}$ ] etc. ('input contrasts'). Palatoalveolars then depalatalized and became retroflex ('output contrasts'). Following Kiparsky (1998), we assume that there are lexical and postlexical derivational levels in Optimality Theory, and that historical changes begin in the postlexical stratum. We are therefore most interested in the postlexical mapping taking input $/ \varphi, \rho^{j} /$ to $[\varsigma, \mathbf{s}]$, as shown below. Note that because this is a postlexical mapping, Richness of the Base is not observed. In particular, there are no input retroflexes because the input to the postlexical is the output of lexical phonology, and Polish lexical phonology did not output [s]. Note also that we treat $\left[\rho^{j}\right]$ as though [?]. The COG results above seem to support this - both 
of these sounds have COG values between [6] and [s]. Also, depalatalization of palatoalveolars most likely preceded retroflexion anyway.

Polish Retroflexion

\begin{tabular}{|c|c|c|c|c|c|c|c|}
\hline Input: & $6 \mathrm{a}_{1}$ & $\int^{\mathrm{j}} \mathrm{a}_{2}$ & SPACE $\geq 1 / 2$ & $*$ IDENT & *MERGE & SPACE $\geq 1$ & ${ }^{*} \mathrm{c} /{ }^{*} \mathrm{~S}$ \\
\hline a. & $6 \mathrm{a}_{1}$ & $\int \mathrm{a}_{2}$ & $* !$ & 8 & & * & $*$ \\
\hline b. & $6 \mathrm{a}_{1,2}$ & & & $*$ & $* !$ & & * \\
\hline c. & $6 \mathrm{a}_{1}$ & & & * & & $x$ & ** \\
\hline
\end{tabular}

Subscripts refer to words, in order to make clear what the output correspondent of an input word is. It should be clear that faithful (29)a would win were IDENT highest ranking, as must have been the case prior to this sound change. A reranking of IDENT and SPACE $\geq 1 / 2$ rules out this undispersed contrast. In such a case, neutralization as in (29)b is a real possibility, but in Polish SPACE was satisfied by means of dispersion of the contrast, (29)c. This candidate is favored by $*$ MERGE, which penalizes any output word having two input correspondents, as in (29)b. In effect, *MERGE is a faithfulness constraint that directly penalizes neutralization. This is not the only way to capture the difference between (29)b-c. We might for example substitute for Ident two constraints like DEP[alveolopalatal] $\gg$ DEP[retroflex], ranked as indicated. The first would penalize a change to [६], the second a change to [s].*MERGE is interesting in offering a means of avoiding such an appeal to feature-specific, unidirectional faithfulness in cases like this, in favor of a more principled explanation. For arguments that *MERGE is necessary independently, see Padgett (2003a).

Hall (1997a) argues that a sound change affecting Sanskrit, by which palatoalveolars became retroflexes (e.g., [ []$>[s]$ ), was motivated by the presence, or perhaps simultaneous acquisition, in that language of an alveolopalatal series (e.g., [६]). The data, and Hall's explanation, anticipate in important respects what we have laid out for Polish. Hall's account differs from ours in being rooted in distinctive feature theory. Specifically, Hall assumes that both [f] and [6] are [-anterior, +distributed], and that no features in fact distinguish these segments. The idea is that a language therefore can never contrast both. Retroflexion in Sanskrit was a means of preserving the two series instead of neutralizing them.

Our approach differs primarily in relying not on featural identity but perceptual similarity. (See the discussion in Zygis 2003a,b and Zygis and Hamann 2003 also.) Hall's account is appealing so long as we can maintain that palatoalveolars and alveolopalatals never contrast. Unfortunately, the sounds $[6]$ and $\left[\mathrm{f}^{j}\right]$ did contrast in Polish before retroflexion occurred, as we have seen, so they cannot in fact be featurally identical. They are also distinguished in Modern Polish as allophones (see the discussion above figure (12)). The Polish distinction cannot be based on palatalization, it should be noted, since alveolopalatals are by definition palatalized. It seems we must therefore adopt an approach that can treat distinctiveness as a matter of more or less, as we advocate here.

\section{$7 \quad$ Russian retroflexion}

In this section we consider extending the proposed account of Polish retroflexion to Russian. The facts are more complicated, and our discussion will not be conclusive, but we will point up some directions for further research. 
To remind the reader, the essentials of Russian retroflexion are indicated below. Recall that palatalized dentals did not become alveolopalatals as in Polish.

\begin{tabular}{|c|c|c|c|c|}
\hline \multicolumn{2}{|c|}{ Input contrasts } & & \multicolumn{2}{|c|}{ Output contrasts } \\
\hline S & $s^{j} \quad \rho^{j}$ & & s & $s^{j}$ \\
\hline $\mathrm{Z}$ & $z^{j} \quad 3^{j}$ & $>$ & $\mathrm{Z}$ & $z^{j}$ \\
\hline$T$ & $\mathrm{t}^{\mathrm{j}} \widetilde{\mathrm{tf}^{\mathrm{j}}}$ & & $\overparen{\text { ts }}$ & $\mathrm{t}^{\mathrm{j}} \widetilde{\mathrm{tg}}^{\mathrm{j}}$ \\
\hline & $\mathrm{d}^{\mathrm{j}}$ & & & $\mathrm{d}^{\mathrm{j}}$ \\
\hline
\end{tabular}

Seen in light of the account for Polish, the Russian data raise two puzzles. First, why did retroflexion occur if $\left[\mathrm{s}^{j}\right]>[\mathrm{c}]$ did not? The account for Polish presupposes that retroflexion was conditioned by the existence of the alveolopalatal series. Second, why did [tf] fail to undergo retroflexion as the palatoalveolar fricatives did?

Regarding the first question, recall the discussion of $\left[\mathrm{s}^{\mathrm{j}}\right]$ in figures (15) and (17). There we observed that COG values for this sound approached, or overlapped with, those for [6] and [0]. This occurs toward the offset of [ $\left.\mathrm{s}^{\mathrm{j}}\right]$, where the palatal off-glide is more influential. This fact suggests the simplest line of explanation: pursue the same account as for Polish, but substituting $\left[\mathrm{s}^{j}\right]$ for $[\mathrm{c}]$. Perceptual experiments would help in understanding the extent to which $\left[\mathrm{s}^{j}\right]$ is indeed similar to [S], in order to gauge the feasibility of such an account.

A second possibility worth mentioning is that $/ \mathrm{s}^{\mathrm{j}} /$ was $[\mathrm{c}]$ in dialects where retroflexion orginated, and retroflexion spread to other Russian dialects from there. Palatalized dentals are realized as alveolopalatals in some north and central European Russian dialects today (Kuznetsova 1969). However, we are aware of no sources suggesting such an origin for Russian retroflexion.

Finally, it is possible that the debatable Russian phonemes [6:, z:] were instrumental. These sounds are historically contractions of other sibilants, hence their tendency to be long (at least intervocalically). The voiced member [z:] is now virtually obsolete, pronounced as

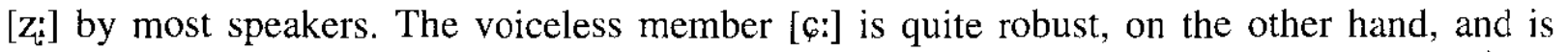
clearly derived from underlying sequences of sibilants in many instances, e.g., /myz+ $t \rho i n a /$

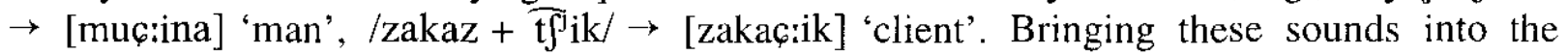
picture of contrasts suggests a third possible answer to our first puzzle, why retroflexion occurred. These sounds would play precisely the role played by alveolopalatals in our account for Polish:

\begin{tabular}{|c|c|c|c|c|c|c|}
\hline \multicolumn{2}{|c|}{ Input contrasts } & & \multicolumn{4}{|c|}{ Ouput contrasts } \\
\hline$S^{j}$ & 6: $\int^{j}$ & & $\mathrm{~S}$ & $s^{j}$ & 6: & S \\
\hline$z^{j}$ & z: $3^{\mathrm{j}}$ & $>$ & $\mathrm{z}$ & $\mathrm{z}^{\mathrm{j}}$ & Z: & Z \\
\hline $\mathrm{t}^{\mathrm{j}}$ & $T \mathrm{tg}$ & & $\widetilde{\mathrm{ts}}$ & $t^{j}$ & & \\
\hline $\mathrm{d}^{\mathrm{j}}$ & & & & $d^{j}$ & & \\
\hline
\end{tabular}

Appealing to these Russian alveolopalatals is tempting, since $\left[\mathrm{tq}^{\mathrm{j}}\right]$ did not depalatalize or retroflex. Perhaps this was because there was no alveolopalatal affricate (long or otherwise) with which it contrasted! Yet this account faces some challenges. First, it is unclear that contraction occurred early enough to play the role for alveolopalatals envisioned here. The sound $[6]$ is still, or was recently, pronounced $[\widehat{6 t \bar{\epsilon}}]$ or $\left[\int \overline{\mathrm{tf}^{3}}\right]$ by speakers of some dialects, particularly St. Petersburg. If they were transparent sequences at the time retroflexion 
occured, it is less obvious that we can appeal to them to motivate that sound change: $[\widehat{c t c}]$ or $\left[\int^{\mathrm{tg}}\right]$ differ from $\left[\mathrm{\rho}^{\mathrm{j}}\right]$ already in number of segments. Indeed, their current length, at least in some environments, complicates any claim that $[\zeta]$ versus $\left[\rho^{j}\right]$ is perceptually difficult. Finally, if we invoke [6:] and [4:] as phonemes at the time of retroflexion, we face a new challenge of assessing whether the contrast between these sounds and the palatalized dentals should have been disfavored as well, and why it was maintained. Recall the suggestion above that $\left[\mathrm{s}^{\mathrm{j}}\right]$ and $\left[\mathrm{c}^{\mathrm{i}}\right]$ are perceptually close.

Turning to the second question, why the palatoalveolar affricate did not undergo retroflexion, one possible answer follows from drawing [6:, z:] into the account, as we just noted. (See (31).) However, putting the latter sounds aside, and appealing once again to the palatalized dentals as the cause of retroflexion, there is a second account for this puzzle worth pursuing. As the diagram below suggests, there is reason to suppose that not all palatalized dentals are equally similar to their corresponding palatalized palatoalveolars. In particular, perhaps $\left[\mathrm{t}^{\mathrm{j}}\right]$ is not as similar to $\left[\mathrm{tf}^{\mathrm{j}}\right]$ as $\left[\mathrm{s}^{\mathrm{j}}, \mathrm{z}^{\mathrm{j}}\right]$ are to $\left[\mathrm{f}^{\mathrm{j}}, 3^{\mathrm{j}}\right]$. (Compare (32) to (30).)

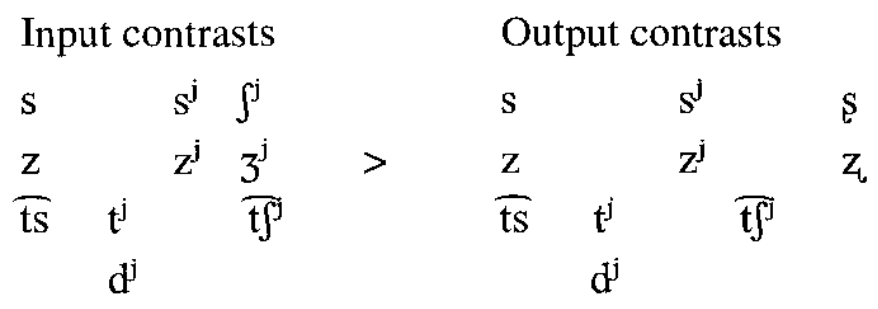

This idea is plausible because palatalized stops differ from palatalized fricatives in having less fricative noise. What noise there is occurs at the offset of palatalized stops. These can sound affricated to varying degrees, depending on the speaker and dialect. To the extent that these stops lack frication at offset, they will lack significant COG cues (which are due to fricative noise) with which to resemble palatoalveolar fricatives. This sets these sounds apart from the dental fricatives, which by nature will bear significant COG values.

The facts of Belorussian might provide some evidence for this latter explanation for $\left[\widehat{\mathrm{t} \mathrm{j}^{\mathrm{j}}}\right]$. Compare the relevant scenarios in Polish, Russian, and Belorussian. In Polish, all palatalized dentals became alveolopalatals, in particular both fricatives and stops, with the latter affricating (see (33)a). The affricate [tc], given its fricative portion, might have

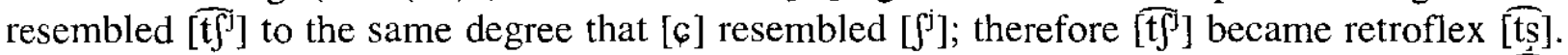
To the extent that Russian [ $\mathrm{t}^{\mathrm{j}}$ ] lacked any such fricative component, it would resemble [t? $]$ less (see (33)b). Belorussian arguably represents an intermediate case. In that language the palatalized stops affricated, as in Polish, though not becoming alveolopalatals. (See (33)c.) Interestingly, in this language, retroflexion affected the palatalveolar affricate, as it did in Polish.
a. Polish
b. Russian
c. Belorussian
c $\quad\left(\rho^{j}>s\right)$
$\mathrm{s}^{\mathrm{j}} \quad\left(\mathrm{\rho}^{\mathrm{j}}>\mathrm{s}\right)$
$s^{j} \quad\left(\rho^{j}>s\right)$
t6 $\left.\widetilde{\left(\mathrm{tg}^{\mathrm{j}}\right.}>\overparen{\mathrm{ts}}\right)$
$\left.\mathrm{t}^{\mathrm{j}} \quad \frac{\left(\mathrm{t}^{\mathrm{j}}\right.}{\mathrm{s}}>\mathrm{t \rho}\right)$
$\left.\mathrm{ts}^{\mathrm{j}} \quad \widehat{(\mathrm{t} \mathrm{j}}>\mathrm{ts}\right)$

The considerations in this section certainly suggest that Russian retroflexion might receive an account based on the same principles applied to Polish. Indeed, we have suggested ways in which the Russian complications might themselves provide further support for the account. Pursuing these ideas is a task for future research. 


\section{$8 \quad$ Conclusion}

A good deal of recent work argues that some (non-assimilatory) allophonic rules, which as a class remain highly mysterious within phonological theory, might be explained as contrast dispersion effects. (See references in the introduction.) We have added Polish and Russian retroflexion to this list: in these languages, non-alveolopalatal postalveolars are allophonically realized as retroflex, rather than palato-alveolar. We have argued that this is directly tied to the existence of the alveolopalatals in Polish (and in Russian perhaps due to the palatalized dentals). From an historical perspective, retroflexion might similarly be rescued from its status as an 'unconditioned' sound change. The appeal to perceptual distinctiveness to explain retroflexion receives independent support from two sources. First, our acoustic results lend support, though perceptual studies that test the claims more directly are called for. Second, the typology supports it. As we saw, there is a significant number of languages having contrasts like [G] versus [s] while lacking [ $[$ ] altogether. Such cases are an embarrassment to any theory which does not take perceptual distinctiveness of contrast into account, and in particular which place palatalveolars at the pinnacle of postalveolar unmarkedness. In such theories, inventories like that of Polish or Penkingese cannot be explained.

The analysis here is of interest also in extending Dispersion-Theoretic principles to consonants (see also Padgett 2002). Though the 'perceptual map' of vowels is better understood than that of consonants, we expect the same principles to be of use in both domains.

While these results are encouraging, we look forward to bringing perceptual data to bear, and exploring the case of Russian further.

\section{Acknowledgments}

We are greatful to Silke Hamann, T. Alan Hall, Junko Ito, Armin Mester, and audiences at the South Western Optimality Theory Conference, University of Arizona; the Workshop on Phonetics-Phonology Interactions, Schloss Freudental, Konstanz; and the Phonology Forum, Kobe, Japan for comments on this paper.

\section{References}

Borkovskii, V. I. \& P. S. Kuznetsov. 1963. Istoricheskaia grammatika russkogo iazyka. Moscow: Akademiia Nauk SSSR.

Bradley, T. 2001. The phonetics and phonology of rhotic duration contrast and neutralization. Ph.D. dissertation, Pennsylvania State University.

Carlton, T. R. 1991. Introduction to the phonological history of the Slavic languages. Columbus, OH: Slavica Publishers.

Chernykh, P. 1962. Istoricheskaia grammatika russkogo iazyka. Moscow: Gosudarstvennoc UchebnoPedagogicheskoc Izdatel'stvo Ministerstva Prosveshchenija RSFSR.

Chomsky, N. 1957. Syntactic Structures. The Hague: Mouton.

Evers, V., H. Rectz \& A. Lahiri. 1998. Crosslinguistic acoustic catcgorization of sibilants independent of phonological status. Journal of phonetics 26: 345-370.

Flemming, E. 2002. Auditory Representations in Phonology.New York \& London: Routledge

Flemming, E. to appear. Contrast and perceptual distinctiveness. In Haycs, B., R. Kirchner \& D. Steriade (eds.) Phonetic bases of markedness. Cambridge: Cambridge University Press. 
Forrest, K., G. Weismer, P. Milenkovic \& R. Dougall. 1988. Statistical analysis of word-initial voiceless obstruents: preliminary data. Journal of Acoustical Society of America 84.1: 115-123.

Gordon, M., P. Barthmaier \& K. Sands. 2002. A cross-linguistic acoustic study of voiceless fricatives. Journal of the International Phonetic Association 32: 141-174.

Hall, T. A. 1997a. The historical development of retroflex consonants in Indo-Aryan. Lingua 102: $203-221$.

Hall, T. A. 1997b. The Phonology of Coronals. Amsterdam: Benjamins.

Hamann, S. 2003. The phonetics and phonology of retroflexes. Utrecht: LOT.

Hamann, S. \& M. Rochoń. 2002. Preferences in sibilant fricative systems: postalveolar puzzlement in Slavic languages. Poster presented at LabPhon 8, Yale University.

Heinz, J. M. \& K. Stevens. 1961. On the properties of voiceless fricative consonants. Journal of the Acoustical Society of America 33.5: 589-596.

Hughes, G. W. \& M. Halle. 1956. Spectral properties of fricative consonants. Journal of the Acoustical Society of America 28.2: 303-310.

Itô, J. \& A. Mester. to appear. Anti-palatalization as a systemic effect. Proceedings of CSL 2003.

Jones, D. \& D. Ward. 1969. The phonetics of Russian. Cambridge: Cambridge University Press.

Jongman, A., R. Wayland \& S. Wong. 2000. Acoustic characteristics of English fricatives. Journal of Acoustical Society of America 108.3: 1252-1263.

Keating, P. 1991. Coronal places of articulation. In Paradis, C. \& F. Prunet (eds.) The Special Status of Coronals: Internal and External Evidence. San Diego: Academic Press; 29-48.

Kingston, J. \& R. Diehl. 1994. Phonetic knowledge. Language 70.3: 419-454.

Kiparsky, P. 1998. Paradigm effects and opacity. Ms., Stanford University.

Kochetov, A. \& A. Lobanova. 2003. Place and manner contrasts in Komi-Permyak obstruents: an acoustic study. Proceedings of the 15th International Congress of Phonetic Sciences, Barcelona.

Kuznetsova, A. 1969. Nekotorye voprosy foneticheskoi kharakteristiki iavleniia tverdosti - miagkosti v russkikh govorakh. In: S. Vysotskii (ed.) Eksperimental'no-foneticheskoe izuchenie russkikh govorov. Moscow: Nauka; 35-137.

Ladefoged, P. 2001. Vowels and consonants. London: Blackwell.

Ladefoged, P. \& I. Maddieson. 1996. The sounds of the world's languages. Cambridge, MA: Blackwell.

Liljencrants, J. \& B. Lindblom. 1972. Numerical simulation of vowel quality systems: the role of perceptual contrast. Language 48.4: 839-862.

Lindblom, B. 1986. Phonetic universals in vowel systems. In J. Ohala \& J. Jaeger (eds.) Experimental phonology. Orlando: Academic Press; 13-44.

Maddieson, I. 1984. Patterns of Sounds. Cambridge: Cambridge University Press.

Maddieson, I. \& K. Precoda. 1992. UPSID and phoneme, user manual. Ms., University of California, Los Angeles.

Mann, V. \& S. Soli. 1991. Perceptual order and the effect of vocalic context on fricative perception. Perception and Psychophysics 49.5: 399-411.

Martinet, A. 1952. Function, structure, and sound change. Word 8.1: 1-32.

Martinet, A. 1955. Economie des Changements Phonetiques. Berne: Francke.

Minkova, D. \& R. Stockwell. 2003. English vowel shifts and 'optimal' diphthongs: is there a logical link? In: E. Holt (ed.) Optimality Theory and language change. Kluwer Academic Press.

Ní Chiosáin, M. \& J. Padgett. 2001. Markedness, segment realization, and locality in spreading. In: L. Lombardi (ed.) Segmental phonology in Optimality Theory: constraints and representations. Cambridge: Cambridge University Press; 118-156.

Padgett, J. 2001. Contrast dispersion and Russian palatalization. In: E. Hume \& K. Johnson (eds.) The role of speech perception in phonology. San Diego, CA: Academic Press; 187-218.

Padgett, J. 2002. Systemic contrast and Catalan rhotics. Ms., University of California, Santa Cruz.

Padgett, J. 2003a. Contrast and post-velar fronting in Russian. Natural language and linguistic theory 21.1: 3987.

Padgett, J. 2003b. The emergence of contrastive palatalization in Russian. In E. Holt (ed.) Optimality Theory and language change. Dordrecht: Kluwer Academic Press; 307-335. 
Prince, A. \& P. Smolensky. 1993. Optimality theory: constraint interaction in generative grammar. Ms., Rutgers University, New Brunswick, NJ, and University of Colorado, Boulder.

Repp, B. 1981. Two strategies in fricative discrimination. Perception and psychophysics 30.3: 217-227.

Rospond, S. 1971. Gramatyka historyczna jezyka polskiego. Warszawa: Panstwowe Wydawnictwo Naukowe.

Sanders, N. 2003. Opacity and sound change in the Polish lexicon. Doctoral disscrtation, University of California, Santa Cruz.

Schwartz, J.-L., L.-J. Boë, N. Vallée \& C. Abry. 1997. The dispersion-focalization thcory of vowel systems. Journal of phonetics 25: 255-286.

Stieber, Z. 1962. Rozwoj fonologiczny jezyka polskiego. Warszawa: Panstwowe Wydawnictwo Naukowe.

Sticher, Z. 1968. The phonological development of Polish. Ann Arbor: University of Michigan.

Trask, R.L. 1997. The history of Basque. New York: Routledge.

Whalen, D. 1981. Effects of vocalic formant transitions and vowel quality on the English [s]-[S] boundary. Journal of Acoustical Society of America 69.1: 275-282.

Whalen, D. H. 1991. Perception of the English /s/ - /S/ distinction relies on fricative noises and transitions, not on brief spectral slices. Journal of Acoustical Society of America 90.4: 1776-1785.

Wicrzchowska, B. 1980. Fonetyka i fonologia jezyka polskiego. Wroclaw, Warszawa: Zaklad Narodowy im. Ossolinskich: Wydawnictwo Polskiej Akademii Nauk.

Zsiga, E. 1995. An acoustic and electropalatographic study of lexical and postlexical palatalization in American English. In B. Connell \& A. Arvaniti (eds.) Phonology and phonetic evidence: papers in laboratory phonology IV. Cambridge: Cambridge University Press; 282-302.

Zsiga, E. 2000. Phonetic alignment constraints: consonant overlap and palatalization in English and Russian. Journal of phonetics 28: 69-102.

Zygis, M. 2003a. Phonetic and phonological aspects of Sibilants in Slavic Languages. This volume.

Zygis, M. 2003b. The role of perception in Slavic sibilant systems. In Kosta, P., J. Blaszczak, J. Frasck, L. Geist \& M. Zygis (eds.) Investigations into formal Slavic linguistics. Berlin: Peter Lang Verlag; 137-154.

Zygis, M. \& S. Hamann. 2003. Perceptual and acoustic cues of Polish coronal fricatives. Proceedings of the 15th International Congress of Phonetic Sciences, August 3-9, Barcelona; 395-398. 